\title{
Hierarchical ISI-1 zeolite catalyst for hydroconversion of long-chain paraffins $\dagger$
}

\author{
Sreeprasanth Pulinthanathu Sree, *a Sambhu Radhakrishnan, Tom Van der Donck, ${ }^{c}$ Gina (iD) ab Lisa Geerts, ${ }^{a}$ \\ Vanbutsele, ${ }^{a}$ Eric Breynaert, $\quad{ }^{a b}$ Jin Won Seo ${ }^{c}$ and Johan A. Martens \\ *a \\ (iD)
}

The hierarchization via desilication of a less studied zeolite, but with particular potential for catalytic applications, belonging to the TON type zeolite family, viz. ISI-1, and its impact on catalytic performance in hydroconversion of model long chain $n$-alkanes are presented. The diffusivity of heavy molecules within monodimensional micropore system zeolites with TON frameworks is limited and the activity is concentrated in the rim of the crystals, referred to as pore mouth catalysis. Desilication has proved to be an efficient strategy for hierarchization, increasing the number of pore mouths as revealed by HR-SEM and TEM. Though notable inhomogeneity in the dispersion of platinum nanoparticles over individual crystals was evidenced via SEM at high resolution, the catalyst presented high isomerization yields.

Zeolites find ample applications in catalysis, intrinsically providing acidity from Brønsted $(\mathrm{OH}$ group bridging Si and $\mathrm{Al}$ ) and Lewis (Al) acid sites and enabling shape selective catalysis. The exclusive presence of micropores however results in diffusion limitations and reduced accessibility of the active sites, representing the major drawback of zeolites in industrial processes like hydrocracking, isomerization, oxidation, etc. ${ }^{1}$ Extra-large pore zeolites have been presented as a solution, but their use is limited because of their low acidity, low thermal stability and unidirectional pore system. ${ }^{2}$ 'Hierarchically' structured zeolites, incorporating at least two levels of porosity, namely the intrinsic zeolitic microporosity and mesoporosity introduced during or after synthesis, could assist in overcoming the mass transfer limitations. The introduction of mesopores provides enhanced accessibility to the micropores bearing the active sites. ${ }^{3}$ Hierarchical zeolites can be synthesized either by templating (bottom up processes) or by demetallation techniques (top down processes). ${ }^{4}$

The templating method involves zeolite crystallization in the presence of mesopores forming a hard (carbon black, ${ }^{5}$

\footnotetext{
${ }^{a}$ Center for Surface Chemistry and Catalysis - Characterization and Application Team (COK-KAT), KU Leuven, Celestijnenlaan 200F, Box 2461, B-3001 Heverlee, Belgium.E-mail: sree.psree@kuleuven.be, johan.martens@kuleuven.be

${ }^{b}$ NMRCoRe, KU Leuven, Celestijnenlaan200F box 2461, 3001-Heverlee, Belgium

${ }^{c}$ Department of Materials Engineering, University of Leuven, Leuven, 3000, Belgium $\dagger$ Electronic supplementary information (ESI) available. See DOI: 10.1039/ d0cy02105a
}

carbon nanotubes, aerogels, ${ }^{6}$ polymers, etc.) or a soft (supramolecular templates like microemulsions, ${ }^{7}$ surfactant mediated processes, ${ }^{8}$ etc.) template. The post-synthetic removal of the template opens up mesopore channels in the structure. The upscaling of such templating syntheses is however difficult, considering the cost of the templates.

In the demetallation method, aluminium atoms can be removed from the structure either by acid treatment or by steaming. ${ }^{9,10}$ Such de-alumination procedures have been widely used in the synthesis of ultra-stable Y zeolites used for fluid catalytic cracking. Some reports however suggest that the mesopores introduced by de-alumination are present as cavities within the crystal, without significantly affecting the intra-crystalline diffusion. ${ }^{11}$

Desilication is one of the most effective methods to introduce hierarchical porosity in zeolites. ${ }^{12,13}$ This process involves selective extraction of $\mathrm{Si}$ atoms from the framework, resulting in the formation of interconnected mesopores, accessible from the zeolite surface. These mesopores have been shown to assist in overcoming diffusion limitations observed in pure microporous zeolites, ${ }^{14}$ resulting in enhanced catalytic performance. Reported applications include mesoporous ZSM-5 in 1-hexene aromatization and isomerization, ${ }^{15}$ mesoporous $\mathrm{ZSM}-22$ (and $\mathrm{Pt} / \mathrm{ZSM}-22$ ) in $n$-octane hydroisomerization ${ }^{16}$ and hierarchical mordenite in naphthalene alkylation. ${ }^{17}$ Desilication procedures can easily be upscaled and are environmentally friendly, since only alkali is involved in the process. The extent of desilication is determined by process parameters such as temperature, reaction time, and alkali concentration. The framework stability, $\mathrm{Si} / \mathrm{Al}$ ratio and framework $\mathrm{Al}$ distribution of the 
zeolite play a crucial role in the efficiency of the desilication process. $^{13,18}$

Zeolites with a TON framework (e.g., H-ZSM-22) have been demonstrated as excellent catalysts for hydroisomerization of long-chain paraffins. ${ }^{19-22}$ These zeolites are made up of 5, 6 and 10 membered rings forming a tubular pore system with 10 membered ring openings. ${ }^{21,23}$ Their application in catalysis is limited by the slow diffusivity of heavy molecules, induced by the monodimensional tubular micropore system. Their activity is hence concentrated at the rim of the crystals, ${ }^{24}$ referred to as pore mouth catalysis. ${ }^{24}$ The blocking of the pore opening renders the acid sites in the whole channel inaccessible and leads to fast catalyst deactivation as well. ${ }^{25}$ The catalytic activity of TON framework zeolites hence could be increased by hierarchization, providing enhanced active site accessibility. After desilication using $\mathrm{NaOH}, \mathrm{Pt} / \mathrm{H}-$ ZSM-22 was reported to exhibit superior activity in hydroisomerization of long chain and branched alkanes like n-nonadecane and pristane (2,6,10,14-tetramethylpentadecane), even though hierarchization by desilication also induced a $50 \%$ reduction in the density of the acid sites. ${ }^{26-28}$ The enhanced activity was attributed to the improved accessibility of the acid sites. Upon desilication, also theta-1 zeolite (TON framework type), applied in the oligomerization of propene to diesel, has been reported to exhibit superior activity, improved selectivity and enhanced resistance to deactivation. ${ }^{29}$ Hierarchization was also shown to exert a promotional effect in the oligomerization of 1-butene on NU10 zeolite, again a TON framework type zeolite. ${ }^{25}$ In this work, the hierarchization of ISI- $1,{ }^{30}$ a TON framework type zeolite, which is not commonly studied for its catalytic performance, is investigated. While ISI-1 was first reported in the $1980 \mathrm{~s}$, there are hardly any literature reports on the post synthetic modification or catalytic application of this zeolite. The present work reports the impact of textural modification of ISI-1 on its catalytic performance in the hydroconversion of long chain $n$-alkanes.

\section{Experimental}

\section{Synthesis of ISI-1 zeolite}

Zeolite synthesis was performed according to the procedure reported by Takatsu et al. ${ }^{30}$ A gel with a molar composition of $27 \mathrm{Na}_{2} \mathrm{O}: \mathrm{Al}_{2} \mathrm{O}_{3}: 84 \mathrm{SiO}_{2}: 822$ methanol:1884 water was prepared and transferred into a $120 \mathrm{ml}$ stainless steel autoclave which was kept under dynamic synthesis conditions for $20 \mathrm{~h}$ in an oven at $170{ }^{\circ} \mathrm{C}$. Washed zeolite powder was ion exchanged three times with a $0.5 \mathrm{M} \mathrm{NH} \mathrm{NH}_{4} \mathrm{Cl}$ solution under reflux conditions to remove part of the template, whereafter the powder was washed, dried and calcined at $450^{\circ} \mathrm{C}$.

\section{Preparation of hierarchical ISI-1 zeolite}

The hierarchization of calcined ISI-1 was achieved by desilication via alkaline treatment at $85{ }^{\circ} \mathrm{C}$ using $0.5 \mathrm{M} \mathrm{NaOH}$ for $4 \mathrm{~h}$. The zeolite powder was subsequently ion exchanged with $0.5 \mathrm{M} \mathrm{NH}_{4} \mathrm{Cl}$, washed, dried and calcined. Finally, a mild acid treatment with $0.1 \mathrm{M} \mathrm{HCl}$ at $50{ }^{\circ} \mathrm{C}$ was applied for $2 \mathrm{~h}$ to remove extraneous $\mathrm{Al}$ species followed by washing with distilled water, subsequent drying at $60{ }^{\circ} \mathrm{C}$, and then calcination at $450^{\circ} \mathrm{C}$.

Both the parent and the hierarchical ISI-1 zeolite were converted into bifunctional catalysts by deposition of 0.3 wt\% Pt via incipient wetness impregnation of $\mathrm{Pt}\left(\mathrm{NH}_{4}\right)_{2} \mathrm{Cl}_{2}$. The zeolite containing Pt complex was loaded into quartz microreactor tubes and subjected to oxidation by heating at $400{ }^{\circ} \mathrm{C}$ under oxygen followed by reduction using $\mathrm{H}_{2}$ at the same temperature.

\section{Catalytic testing}

Hydroconversion of $n$-nonadecane $\left(n-\mathrm{C}_{19}\right)$ over the bifunctional catalysts was performed in a fixed bed reactor. The $n-\mathrm{C}_{19}$ feed was diluted to a concentration of $1 \mathrm{~mol} \%$ in $n$-heptane, vaporized and fed onto the catalyst bed under the following reaction conditions: $P=0.45 \mathrm{MPa}, P_{\mathrm{H}_{2}} / P_{\mathrm{HC}}=13$ and $W / F_{\mathrm{C} 19^{\circ}}=4600 \mathrm{~kg} \mathrm{~s} \mathrm{~mol}{ }^{-1}$.

\section{Zeolite characterisation}

PXRD patterns were recorded on an STOE STADI P Combi diffractometer equipped with a $\mathrm{Cu}$ source, a focusing $\mathrm{Ge}(111)$ monochromator $\left(\mathrm{CuK \alpha}_{1}\right.$ radiation, $\left.\lambda=0.154056 \mathrm{~nm}\right)$ and an image plate position sensitive detector (IP-PSD) exhibiting an internal resolution of $0.03^{\circ} 2 \theta$. All measurements were obtained at room temperature.

$\mathrm{N}_{2}$ isotherms were recorded at $77 \mathrm{~K}$ on a Micromeritics TriStar 3000 sorptometer. Before the measurement, the samples were pretreated at $400{ }^{\circ} \mathrm{C}$ under an $\mathrm{N}_{2}$ atmosphere. The micro- and mesopore volumes as well as the surface area were computed using $t$-plot analysis and BET methods, respectively.

${ }^{27} \mathrm{Al}$ magic angle spinning (MAS) NMR spectra were recorded on a Bruker $500 \mathrm{MHz}$ spectrometer (Bruker Avance III; $11.7 \mathrm{~T} ;{ }^{27} \mathrm{Al}$ resonance frequency $130.52 \mathrm{MHz}$ ), equipped with a $4 \mathrm{~mm}$ triple channel $(\mathrm{H} / \mathrm{X} / \mathrm{Y})$ CPMAS probe. The samples were filled in a $4 \mathrm{~mm} \mathrm{ZrO}_{2}$ rotor and spun at 15 kHz. ${ }^{27} \mathrm{Al}$ (resonance frequency $130.52 \mathrm{MHz}$ ) measurements were performed with a flip angle of $\pi / 12$ at $156 \mathrm{kHz}$ RF, 4096 transients and a repetition delay of 2 s. SPINAL-64 high power ${ }^{1} \mathrm{H}$ decoupling was implemented during ${ }^{27} \mathrm{Al}$ spectral acquisition. ${ }^{31}$ The spectra were referenced to $0.1 \mathrm{M} \mathrm{AlNO}_{3}$ solution in $\mathrm{D}_{2} \mathrm{O}\left({ }^{27} \mathrm{Al} \delta=0 \mathrm{ppm}\right)$.

Elemental analysis of the samples was done with ICP performed on an Optima 4300 DV2 (Perkin Elmer). For the determination of the $\mathrm{Al}$ and $\mathrm{Si}$ content, $100 \mathrm{mg}$ of zeolite sample was added to $500 \mathrm{mg}$ of $\mathrm{LiBO}_{2}$ (Aldrich) in a graphite crucible. This was placed in an oven at $1000{ }^{\circ} \mathrm{C}$ for 15 minutes. The molten solidified material was dissolved in 50 $\mathrm{mL}$ of $0.42 \mathrm{~N} \mathrm{HNO}_{3}$ (Sigma Aldrich pro analysis, 65\%). The sample was equilibrated overnight before pipetting the liquid for analysis. Elemental analysis was performed using ICPOES (Optima 4300 DV2, Perkin Elmer). 
FTIR measurements were performed on a Nicolet 6700 spectrometer equipped with a vacuum cell. A self-supporting wafer weighing approximately $10 \mathrm{mg}$ was used for the FT-IR measurements. The sample was evacuated in a vacuum chamber and heated at $400{ }^{\circ} \mathrm{C}$ for $90 \mathrm{~min}$, ramping up the temperature from room temperature at $5{ }^{\circ} \mathrm{C} \mathrm{min}^{-1}$. The spectra were recorded over the range of $400-4000 \mathrm{~cm}^{-1}$ at a resolution of $4 \mathrm{~cm}^{-1}$. The spectra were recorded at different temperatures $\left(200 \& 300{ }^{\circ} \mathrm{C}\right)$ and the sample was subsequently cooled to $150{ }^{\circ} \mathrm{C}$. Adsorption of the probe molecules was performed by exposing the pellet to pyridine at $150{ }^{\circ} \mathrm{C}$ and desorption was done by raising the temperature to 200 and $300{ }^{\circ} \mathrm{C}$. Acid site quantification was performed using the molar extinction coefficient reported by Emeis et $a .^{32}$

HR-SEM was performed on a Nova NanoSEM450 (FEI) scanning electron microscope. The samples were mounted on $\mathrm{Al}$ stubs and observed without any additional coating, using low voltages and a concentric backscattered (CBS) detector in the immersion lens mode.

Transmission electron microscopy (BF-TEM) was performed with a probe-corrected transmission electron microscope (ARM200F cold-FEG, JEOL) operated at an acceleration voltage of $200 \mathrm{kV}$. The samples were prepared by dispersing the powder in 2-propanol and placing a few drops of the solution onto the copper TEM grids covered with a lacey carbon film (Pacific Grid Tech).

\section{Results and discussion}

Elemental analysis indicated a Si/Al ratio of 42 for the parent ISI-1 zeolite. This Si/Al ratio reflected that of the synthesis gel, indicating that all the aluminum in the synthesis gel was incorporated into the zeolite structure. Hierarchical ISI-1 exhibited a $\mathrm{Si} / \mathrm{Al}$ ratio of 50 , due to leaching of the framework Al during desilication and subsequent acid washing.

XRD indicated that the framework retained its structural integrity after desilication (Fig. S1 $\dagger$ ). The $\mathrm{N}_{2}$ adsorption isotherm (Fig. S2 $\dagger$ ) showed an increase in porosity owing to the creation of new mesopores and revealed the formation of hierarchical ISI-1. The micropore volume of the hierarchical sample was doubled by the desilication process. This is not so trivial during desilication of conventional zeolites and could be attributed to the typical structure of the ISI-1 sample (parent) which has long unidirectional micropores, where defects in the crystal can result in complete blocking of the micropores. The hierarchical ISI-1 sample presented a BET surface area of $40 \mathrm{~m}^{2} \mathrm{~g}^{-1}$, whereas that of the parent sample was $27 \mathrm{~m}^{2} \mathrm{~g}^{-1}$.

${ }^{27} \mathrm{Al}$ MAS NMR (Fig. 1) showed two resonances around 54 and $0 \mathrm{ppm}$, corresponding to tetra- and hexa-coordinated $\mathrm{Al}$, respectively, for both the parent and treated hierarchical zeolites. The large peak confirmed the presence of $\mathrm{Al}$ in the tetracoordinated environment in both the parent $(89 \%$ of the total $\mathrm{Al}$ ) and hierarchical ISI-1 (92\% of the total $\mathrm{Al})(\mathrm{ESI} \dagger$ Table S1). The desilicated zeolite exhibited a narrower tetra-

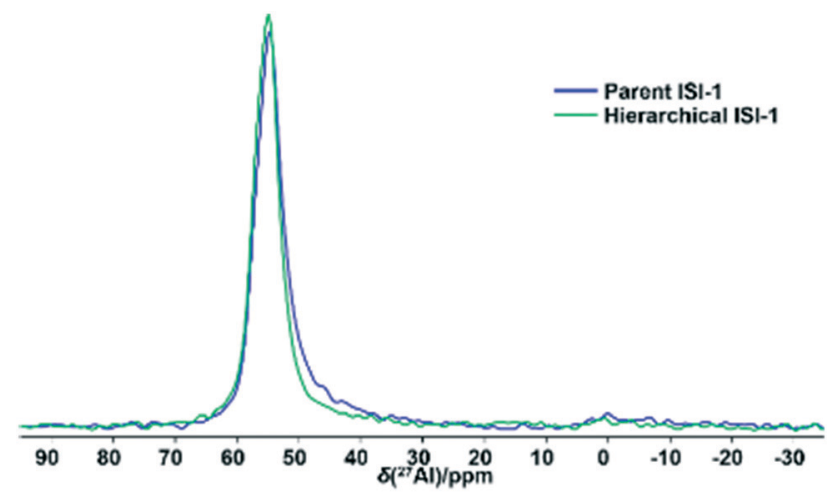

Fig. $1{ }^{27} \mathrm{Al}$ NMR spectra of the parent and hierarchical ISI-1 zeolites.

coordinated $\mathrm{Al}$ resonance and had an $8 \%$ lower total $\mathrm{Al}$ content compared to the parent sample. This could be due to the removal of framework $\mathrm{Al}$, together with $\mathrm{Si}$ atoms. Desilication is known to convert some of the framework $\mathrm{Al}$ into extraframework Al. But in this case, no significant increase in the amount of extraframework $\mathrm{Al}$ was evidenced by ${ }^{27} \mathrm{Al} \mathrm{NMR.}$

The parent and hierarchical samples were observed with HR-SEM after loading with $0.3 \mathrm{wt} \% \mathrm{Pt}$. The parent ISI crystals have a rod-like morphology (Fig. 2a-c). In hierarchical ISI-1, the mesopores are clearly visible (Fig. 2d-f) and accessible from the crystal surface. Desilication leads to fragmentation of crystals, especially in the longitudinal direction which resulted in enhancing the accessibility to the micropores, as evidenced also from $\mathrm{N}_{2}$ physisorption measurements.

The dispersed Pt particles measuring ca. $5 \mathrm{~nm}$ could be observed by HR-SEM. These observations were further confirmed by TEM (Fig. 3). The less dark stripes in the images ( $a$ and $b$ ) indicated the formation of craters along the longer axis of the zeolite. The dark black spots in images $c$ and $\mathrm{d}$ are Pt particles having sizes mostly around $5 \mathrm{~nm}$.

Comprehensive analysis of the sample using HR-SEM showed the distribution of $\mathrm{Pt}$ to be unexpectedly inhomogeneous (Fig. 4). Some crystals were highly covered with Pt nanoparticles, while other crystals had very little platinum. It remains to be investigated whether these inhomogeneities are typical for ISI-1, or are related to the hierarchization process, or may even occur with other zeolites in general. A classic Pt dispersion measurement via chemisorption would not reveal the inhomogeneity. These kinds of heterogeneities were observed in another study using HR TEM tomography on platinum impregnated USY samples, where the heterogeneity was ascribed to the difference in $\mathrm{Al}$ distribution for different zeolite crystals. ${ }^{33}$

The results of acid site quantification via FT-IR coupled temperature programmed adsorption-desorption of pyridine are given in Table 1 . Only $33 \%$ of the theoretical acid sites could be accessed by pyridine (kinetic diameter of $0.54 \mathrm{~nm}$ ) in the parent ISI-1, indicating the presence of accessibility issues due to the needle like crystal morphology (and the micropore structure). 

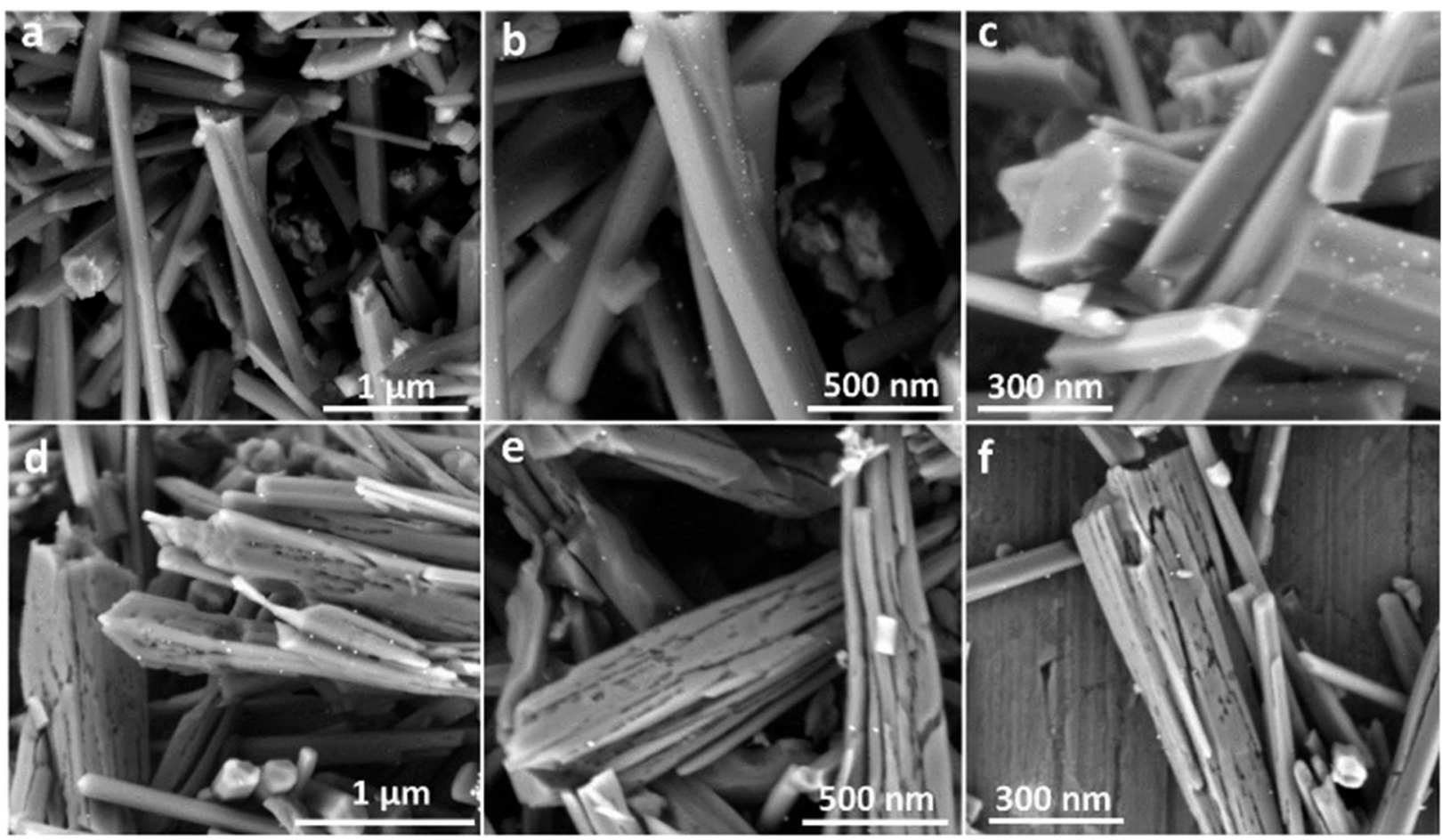

Fig. 2 HR-SEM images of the zeolite catalysts impregnated with 0.3 wt\% Pt. Parent ISI-1 (a-c) and desilicated ISI-1 (d-f).

TON zeolites exhibit a one-dimensional channel system, made up of ten-membered rings running parallel to $\{001\}$, which are elliptical in the cross section with free diameters of 0.47 and $0.55 \mathrm{~nm}$. Hence, sites that are accessed by pyridine could be the ones at or close to the pore mouths. The accessibility increased to $42 \%$ upon desilication. Even though

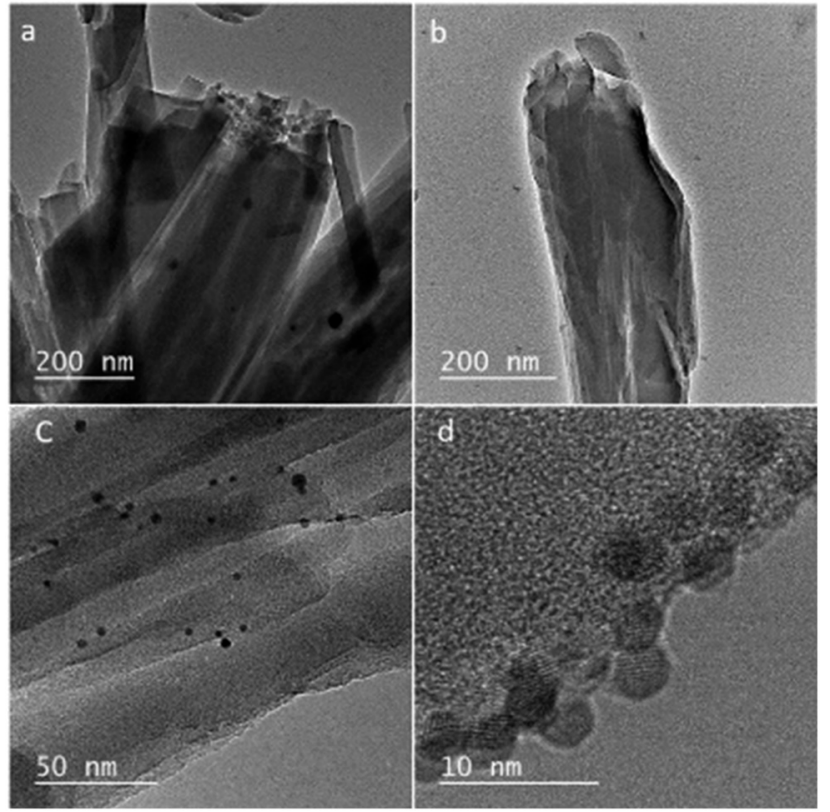

Fig. 3 TEM images at different magnifications (a-d) of the hierarchical ISI-1 zeolite loaded with $0.3 \mathrm{wt} \% \mathrm{Pt}$. the total theoretical acid sites decreased upon desilication due to the decrease in framework $\mathrm{Al}$, the number of acid sites accessible to pyridine was similar for both the parent and hierarchical ISI-1 samples. Desilication did not lead to a decrease in Brønsted acid site density, which is observed in most hierarchization processes. Moreover, desilication leads to opening of more and more pore mouths along the needle shaped crystals, leading to an increase in the amount of accessible acid sites. This is also confirmed by the higher decrease in the area under the peak corresponding to the Brønsted acid $\mathrm{O}-\mathrm{H}$ stretching at $c a .3600 \mathrm{~cm}^{-1}$ in the FTIR spectra (Fig. S3†) for the hierarchical ISI-1 compared to the parent.

\section{Hydroconversion of $n$-nonadecane $\left(n-\mathrm{C}_{19}\right)$}

Prior to the catalytic tests the zeolites were loaded with 0.3 wt $\%$ of platinum by incipient wetness with $\mathrm{Pt}\left(\mathrm{NH}_{4}\right)_{2} \mathrm{Cl}_{2}$ solution followed by drying. Zeolite powder was pressed into pellets $(250-500 \mu \mathrm{m})$ for catalytic testing. Prior to reaction, the catalysts were pretreated under oxygen at $400{ }^{\circ} \mathrm{C}$ with a heating rate of $5{ }^{\circ} \mathrm{C} \mathrm{min}^{-1}$, and then reduced with hydrogen at the same temperature. The reaction products were analyzed on-line with GC. The conversion increases with increasing reaction temperature at a constant contact time. In hydroconversion reactions over bifunctional catalysts, hydroisomerization and hydrocracking occur simultaneously. The isomerization reaction predominates at lower conversions while cracking predominates at higher conversions and hence the isomerization yield goes through 

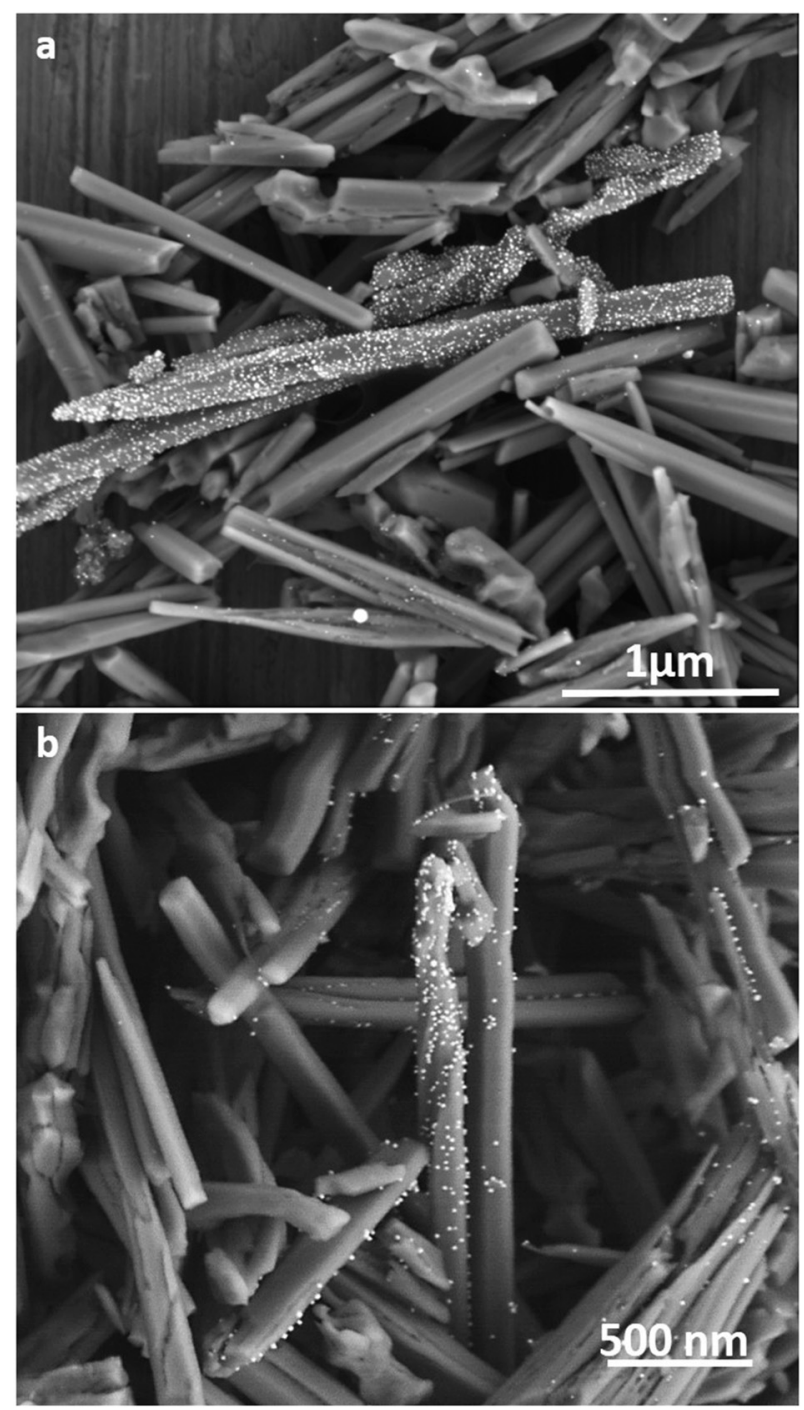

Fig. 4 HR-SEM images at different magnifications (a-b) of hierarchical ISI-1 loaded with $0.3 \mathrm{wt} \% \mathrm{Pt}$, showing heterogeneity in Pt dispersion.

a maximum after which the hydrocracking yield increases. This typical activity trend was observed for both the catalysts and is depicted in Fig. 5. The hierarchical ISI-1 achieved $100 \% n-\mathrm{C}_{19}$ conversion at $290{ }^{\circ} \mathrm{C}$, while the parent ISI-1 required a reaction temperature of $320{ }^{\circ} \mathrm{C}$ to achieve $90 \%$ conversion. A pronounced difference was also observed in the attained maximum hydroisomerization yield: $90 \%$ selectivity for isomers at $95 \%$ conversion for the hierarchical ISI- 1 compared to the $45 \%$ selectivity at $60 \%$ conversion for the parent ISI-1. This improvement in the overall activity as well as in the isomerization yield on hierarchization is very
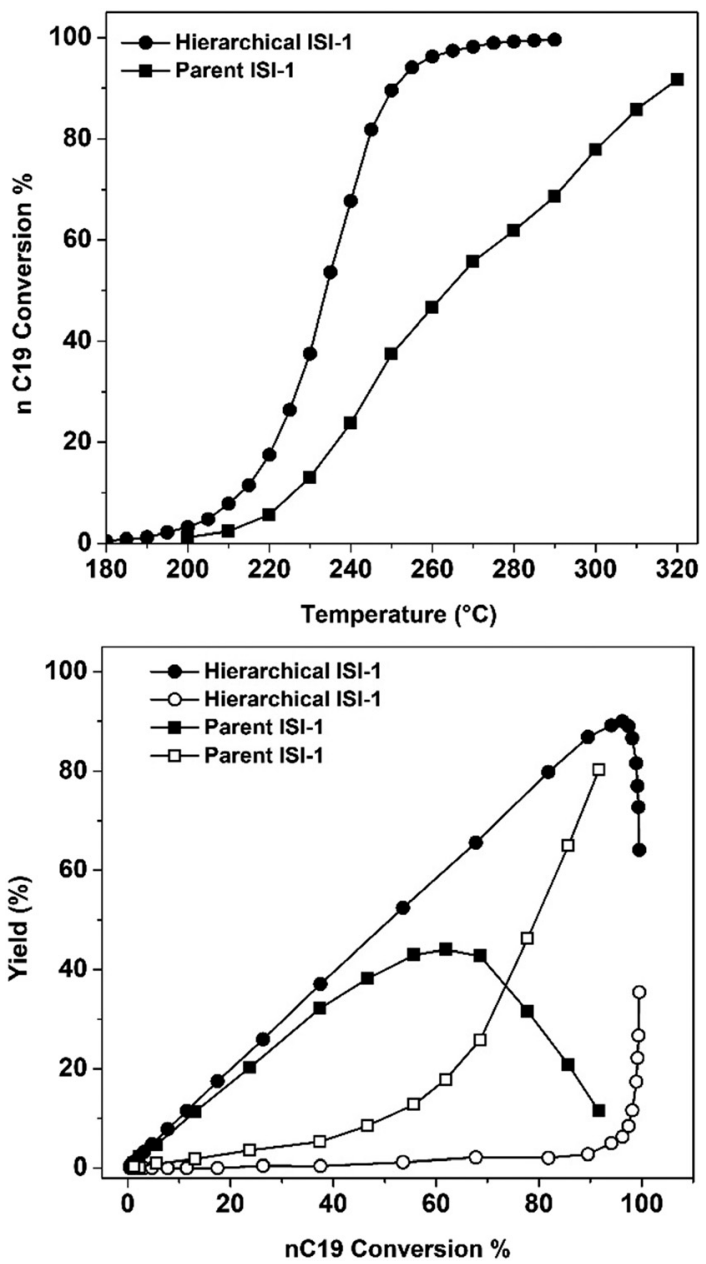

Fig. 5 (top): $n$-Nonadecane conversion for the hierarchical (circle) and conventional (square) ISI-1 zeolites; (bottom): yield of different products - skeletal isomers (closed symbols) and cracked products (open symbols) - for the hierarchical (circle) and conventional (square) ISI-1 zeolites.

pronounced for the ISI-1 samples, and much more than that for other hierarchical TON type zeolites like ZSM-22 investigated previously. ${ }^{27,28}$ The effect of hierarchization on isomerization selectivity was more prominent on the ISI-1 zeolite compared to the same post synthesis treatment applied to H-ZSM-22. ${ }^{27,28}$

While it was evident from HR-SEM that the Pt distribution on the hierarchical ISI-1 sample is very inhomogeneous, the excellent selectivity in the isomerization falls in line with the recent findings that the metal and acid sites need not to be in close proximity to each other but maintaining a nanoscale intimacy between

Table 1 Physicochemical characterization of the parent and hierarchical ISI-1 samples

\begin{tabular}{|c|c|c|c|c|c|c|c|c|}
\hline \multirow[b]{2}{*}{ Sample } & \multirow{2}{*}{$\begin{array}{l}S_{\mathrm{BET}} \\
\left(\mathrm{m}^{2} \mathrm{~g}^{-1}\right)\end{array}$} & \multirow{2}{*}{$\begin{array}{l}V_{\text {micro }} \\
\left(\mathrm{mL} \mathrm{g}^{-1}\right)\end{array}$} & \multirow{2}{*}{$\begin{array}{l}V_{\text {meso }} \\
\left(\mathrm{mL} \mathrm{g}^{-1}\right)\end{array}$} & \multirow{2}{*}{$\begin{array}{l}\mathrm{Si} / \mathrm{Al} \\
\text { ratio ICP }\end{array}$} & \multicolumn{3}{|c|}{$\left.\underline{\text { Brønsted acid site quantity }(\mathrm{mol} \mathrm{kg}}{ }^{-1}\right)$} & \multirow{2}{*}{$\begin{array}{l}{ }^{27} \mathrm{Al} \text { integrated } \\
\text { area/mass }\end{array}$} \\
\hline & & & & & Theoretical & TPD@200 C & TPD@300 ㄷ & \\
\hline Parent ISI-1 & 27 & 0.007 & 0.03 & 42 & 0.39 & 0.13 & 0.1 & 1 \\
\hline Hierarchical ISI-1 & 40 & 0.017 & 0.04 & 50 & 0.33 & 0.14 & 0.1 & 0.92 \\
\hline
\end{tabular}




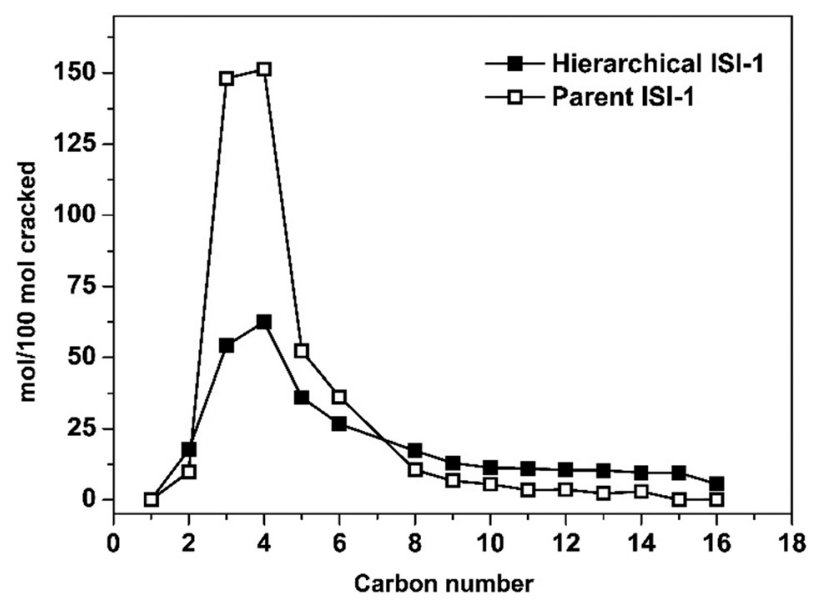

Fig. 6 Molar yields of cracked products expressed per $100 \mathrm{~mol}$ of model molecule cracked at $35 \%$ hydrocracking yield on the conventional ISI-1 (open symbols) and hierarchical ISI-1 catalysts (closed symbols).

the active sites is enough for the catalyst to exhibit such a superior selectivity. ${ }^{34}$

Along with the isomerization/cracking selectivity, another important descriptor of hydroconversion catalysts is the distribution of cracking products. For the parent ISI-zeolite, $\mathrm{C}_{3}-\mathrm{C}_{4}$ products predominated, indicating undesired strong secondary cracking. The hierarchical zeolite showed a significantly lower $\mathrm{C}_{3}-\mathrm{C}_{4}$ yield, indicating inhibition of the secondary cracking pathways qualifying it to be a desirable catalyst in hydroconversion minimizing the formation of undesired light hydrocarbons (Fig. 6). The distribution of $\mathrm{C}_{5}$ products, viz. $n$-pentane $\left(n \mathrm{C}_{5}\right) \&$ isopentane $\left(i \mathrm{C}_{5}\right)$, is a way to investigate the modification of the pore architecture. Skeletal isomerization and multibranched isomer cracking are reported to occur in the pore mouths, while cracking to linear fragments is reported to occur inside the micropores. ${ }^{28}$ The increase in $i \mathrm{C}_{5}$ selectivity in the case of the hierarchical ISI- 1 confirms the generation of more accessible pore mouths via desilication (Fig. 7).

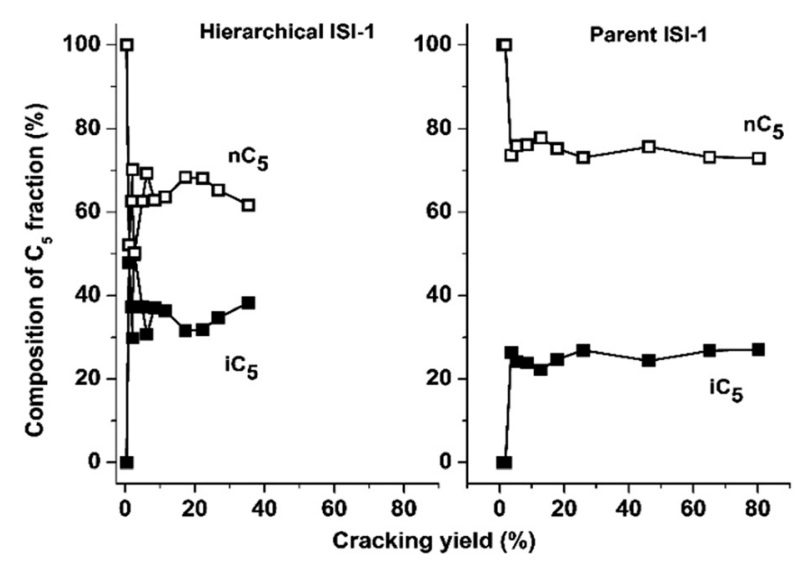

Fig. 7 Composition of the $C_{5}$ cracked product fraction as a function of the hydrocracking yield of model alkanes on the conventional and hierarchical ISI-1 catalysts.

\section{Conclusions}

Creating hierarchical derivatives of ISI-1 zeolite via desilication is demonstrated as an efficient method for fragmenting ISI-1 crystals, improving the catalytic performance of the material. Positive influence was observed on all catalytic descriptors, i.e., conversion, enhanced isomerization selectivity, distribution of cracked products, etc. These effects are attributed to more accessible pore mouths created via desilication. Even though SEM at nanometer resolution revealed a surprising inhomogeneity in the dispersion of platinum nanoparticles over individual crystals, the hierarchical ISI-1 zeolite presented itself as an excellent isomerization catalyst. The findings demonstrate the potential of post-synthesis treatments like desilication in the precise design of catalysts for isomerizationdewaxing processes.

\section{Conflicts of interest}

There are no conflicts of interest to declare.

\section{Acknowledgements}

This work was supported by the Hercules Foundation (AKUL/ 13/21), the Research Foundation Flanders (G0A5417N, G038116N), and by the Flemish Government, department EWI via the Hermes Fund (AH.2016.134). J. A. M. acknowledges the Flemish Government for long-term structural funding (Methusalem). J. W. S. \& J. A. M. acknowledges the Flemish Hercules Foundation (AKUL/13/19). E. B. acknowledges FWO for a 'Krediet aan navorsers' (1.5.061.18N).

\section{References}

1 C. M. A. Parlett, K. Wilson and A. F. Lee, Chem. Soc. Rev., 2013, 42, 3876-3893.

2 J. Pérez-Ramírez, C. H. Christensen, K. Egeblad, C. H. Christensen and J. C. Groen, Chem. Soc. Rev., 2008, 37, 2530-2542.

3 V. Valtchev, G. Majano, S. Mintova and J. Pérez-Ramírez, Chem. Soc. Rev., 2013, 42, 263-290.

4 Y. Wei, T. E. Parmentier, K. P. de Jong and J. Zečević, Chem. Soc. Rev., 2015, 44, 7234-7261.

5 X. Wei and P. G. Smirniotis, Microporous Mesoporous Mater., 2006, 89, 170-178.

6 Y. Tao, H. Kanoh and K. Kaneko, J. Am. Chem. Soc., 2003, 125, 6044-6045.

7 J.-C. Lin and M. Z. Yates, Langmuir, 2005, 21, 2117-2120.

8 P. Prokešová, S. Mintova, J. Čejka and T. Bein, Mater. Sci. Eng., C, 2003, 23, 1001-1005.

9 H. K. Beyer, Mol. Sieves, 2002, 3, 203-255.

10 A. G. Pelmenschikov, E. A. Paukshtis, M. O. Edisherashvili and G. M. Zhidomirov, J. Phys. Chem., 1992, 96, 7051-7055.

11 P. Kortunov, S. Vasenkov, J. Kärger, R. Valiullin, P. Gottschalk, M. F. Elía, M. Perez, M. Stöcker, B. Drescher, G. McElhiney, C. Berger, R. Gläser and J. Weitkamp, J. Am. Chem. Soc., 2005, 127, 13055-13059. 
12 D. Verboekend and J. Pérez-Ramírez, Catal. Sci. Technol., 2011, 1, 879.

13 D. Kerstens, B. Smeyers, J. Van Waeyenberg, Q. Zhang, J. Yu and B. F. Sels, Adv. Mater., 2020, 32, 2004690.

14 J. C. Groen, J. A. Moulijn and J. Pérez-Ramírez, J. Mater. Chem., 2006, 16, 2121.

15 Y. Li, S. Liu, Z. Zhang, S. Xie, X. Zhu and L. Xu, Appl. Catal., A, 2008, 338, 100-113.

16 D. Verboekend, K. Thomas, M. Milina, S. Mitchell, J. PérezRamírez and J.-P. Gilson, Catal. Sci. Technol., 2011, 1, 1331.

17 I. I. Ivanova, A. S. Kuznetsov, E. E. Knyazeva, F. Fajula, F. Thibault-Starzyk, C. Fernandez and J.-P. Gilson, Catal. Today, 2011, 168, 133-139.

18 D. Verboekend and J. Pérez-Ramírez, Chem. - Eur. J., 2011, 17, 1137-1147.

19 J. A. M. Arroyo, G. G. Martens, G. F. Froment, G. B. Marin, P. A. Jacobs and J. A. Martens, Appl. Catal., A, 2000, 192, 9-22.

20 M. C. Claude, G. Vanbutsele and J. A. Martens, J. Catal., 2001, 203, 213-231.

21 P. A. Jacobs and J. A. Martens, Stud. Surf. Sci. Catal., 1986, 28, 23-32.

22 M. C. Claude and J. A. Martens, J. Catal., 2000, 190, 39-48.

23 G. T. Kokotailo, J. L. Schlenker, F. G. Dwyer and E. W. Valyocsik, Zeolites, 1985, 5, 349-351.
24 J. A. Martens, G. Vanbutsele, P. A. Jacobs, J. Denayer, R. Ocakoglu, G. Baron, J. A. Muñoz Arroyo, J. Thybaut and G. B. Marin, Catal. Today, 2001, 65, 111-116.

25 P. Matias, C. Sá Couto, I. Graça, J. M. Lopes, A. P. Carvalho, F. Ramôa Ribeiro and M. Guisnet, Appl. Catal., A, 2011, 399, 100-109.

26 D. Verboekend, A. M. Chabaneix, K. Thomas, J.-P. Gilson and J. Pérez-Ramírez, CrystEngComm, 2011, 13, 3408.

27 J. A. Martens, D. Verboekend, K. Thomas, G. Vanbutsele, J.-P. Gilson and J. Pérez-Ramírez, ChemSusChem, 2013, 6, 421-425.

28 J. A. Martens, D. Verboekend, K. Thomas, G. Vanbutsele, J. Pérez-Ramírez and J.-P. Gilson, Catal. Today, 2013, 218-219, 135-142.

29 C. Martínez, E. J. Doskocil and A. Corma, Top. Catal., 2013, 57, 668-682.

30 K. Takatsu and N. Kawata, Process for producing a crystalline silicate, EP Pat., EP0087017, 1986.

31 B. M. Fung, A. K. Khitrin and K. Ermolaev, J. Magn. Reson., 2000, 142, 97-101.

32 C. A. Emeis, J. Catal., 1993, 141, 347-354.

33 L. I. van der Wal, K. P. de Jong and J. Zečević, ChemCatChem, 2019, 11, 4081-4088.

34 J. Zecevic, G. Vanbutsele, K. P. De Jong and J. A. Martens, Nature, 2015, 528, 245-254. 